\section{THE OCEANOGRAPHICAL MUSEUM AT} $M O N A C O$.

I $\mathrm{N}$ the history of the development of the study of the sea all the sciences find an application, and all were worthily represented at the inauguration of the Oceanographical Museum of Monaco on March 29 of this year. The ceremonies and festivities incident to the occasion have already been chronicled in the columns of NaTURe (April r4, vol. 1xxxiii., p. I9i). It is proposed here to give an impression of the lifework of the Prince of Monaco, which found expression in the solemnities of that occasion. The accompanying illustrations ${ }^{1}$ afford an idea of the magnificence of the building and of the richness of the collections. Fig. I gives a view of the museum from the sca. The scale on which it is built can be judged from the fact that the height of the roof above the lowest masonry is 75 metres. Fig. 2 is the statue of the Prince standing on the bridge of his yacht. It is an artistic work, and a good portrait. It gives fine expression to the modesty as well as to the power of the creator of the great monument in the centre of which it stands.

The museum and the vessels attached to it, with their staffs and general organisation, are only onehalf of the great enterprise which is entitled, "Institut Oceanographique Fondation Albert Ier Prince de Monaco." Its seat is in Paris, where it possesses its own buildings and a rich endowment, both of them the gift of the Prince. It has professors of physical and biological oceanography and of the physiology of marine animals, and the lectures delivered during last year had the most numerous attendance of any in Paris. During the life of the Prince he exercises supreme authority. Both in Paris and at Monaco there is complete organisation for giving effect to his wishes, and, in the event of his death, for carrying on the work without interruption, and on the lines inau-

gurated by himself. Thus continuity and permanence have been assured.

It will be readily realised that the establishment of these two great institutions has not been accomplished without the expenditure of large sums of money and the devotion of much time and labour to it. It is almost impossible for anyone to realise the greatness of the work which is being accomplished without having been intimately connected with it, and even with this advantage the development of the conception is slow. As with all great achievements, it will take at least a generation before it is thoroughly understood and adequately appreciated.

The museum at Monaco bears testimony at every turn to the great lines on which the Prince has himself worked, and in which his work is fundamental. Thus, in the purely hydrographical department, we see his bathymetrical chart of the world, on which

1 For the illustrations in this article we are infebted to the courtesy of the propritor of the Naturzeissenschaftliche Wochenschrift. They are reproduced from photographs hy Prof. Döflein, of Munich, a'd illustrate an aticle by him in that periodical.-Editor. NATURE. all the trustworthy deep soundings are entered. This great document may be said to be the foundation-stone of oceanographical work. Another and much earlier piece of hydrographical work is the current chart of the North Atlantic, which gives the result of his laborious work on board the Hirondelle. By the methodical dispersion of floats, especially constructed to expose the least possible surface above water, along different lines radiating generally from the group of the Azores, by patiently awaiting their recovery, and by then combining their records, he furnished the demonstration that this portion of the ocean is practically a lake, bounded, not by land, but by the motion of its own peripheral waters, thus enclosing a roughly circular portion of the sca, part of which is generally associated with the Sargassum weed and called the Sargasso Sea. The water, thus self-confined in the warm, dry subtropical region, is exposed to powerful evaporation, and to a considerable annual variation of temperature at the surface. The combination of these two thermal factors furnishes the mechanical power 
met with a few miles outside of Monaco. They a large mass of something came out of its mouth close fought to the death, and when killed they were to the yacht and began slowly to sink. The Prince

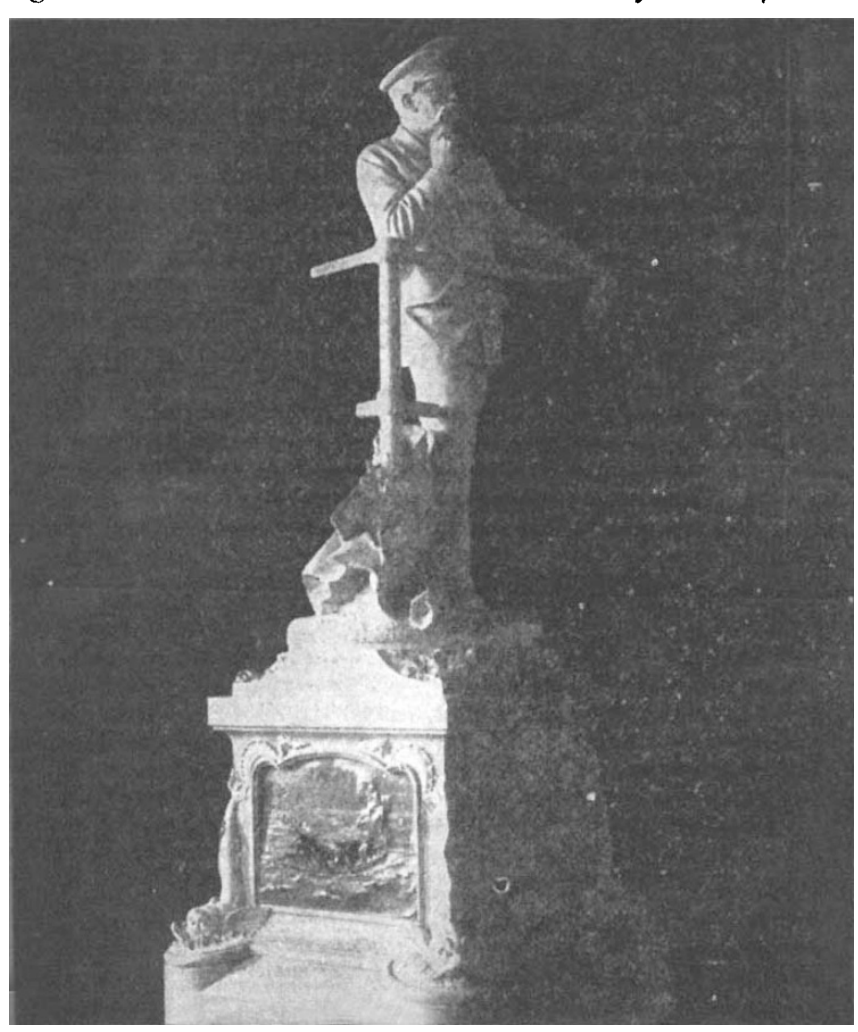

FIg. 2.-Statue of Prince Albert I. of Monaco in the Museum at once jumped into the dinghey, and, with a long landing net, retrieved the object before it sank out of sight. The object is represented in Fig. 5, and is a unique piece. It is a fragment of the gigantic scaled cephalopod which Prof. Joubin, who described it, named Lepidoteuthis Grimaldii.

A healthy cachalot is valued for the spermaceti, or wax, which is contained in its head, and a sick one is still more valued for the ambergris which it may contain. This curious substance, which has at all times been so highly esteemed in pharmacy and perfumery, forms the subject of a very interesting "Account of Ambergris" by Dr. Schweidawer, which was read before the Royal Society on February $13,178_{3}$, and published in the Philo. sophical Transactions, vol. lxxiii., p. 220. From his investigations it appears that ambergris is a by-product of an inflammation of the intestine, which has probably been started by the "beaks" of the cephalopods which it has swallowed, for these are the invariable and characteristic ingredient of all genuine ambergris. He further states that the whalers are convinced that the cachalot feeds only on squids, which, when unmutilated, must be of great size. One whaler reported a case where the whale in its death-throe rendered a single tentacle, which, though incomplete from having been partially digested, still measured 29 feet in length, and he held that this justifies the common saying of the whalers that the squids are the biggest fish in the sea.

The work of the Prince amongst the toothed Cetaceans has had an interesting sentimental

towed in and beached on what is now the new harbour of Monaco.

Not far from the Orca is a skeleton, Fig. 4, of the best known of the toothed Cetaceans, the cachalot or sperm-whale. It was not taken by the Prince himself, but he was present at its capture, and his scientific instinct enabled him to seize an opportunity which would probably have been missed by another. The cachalot had been struck by a crew of whalers from Terceira, one of the islands of the Azores. The Prince followed the chase in his yacht, and was close to the animal when it became evident that its end had come. At this moment these animals always charge whatever they see, and in their death agony they usually render whatever they have last eaten. This animal charged the Princesse Alice, but the charge did not get home. The animal stopped, and

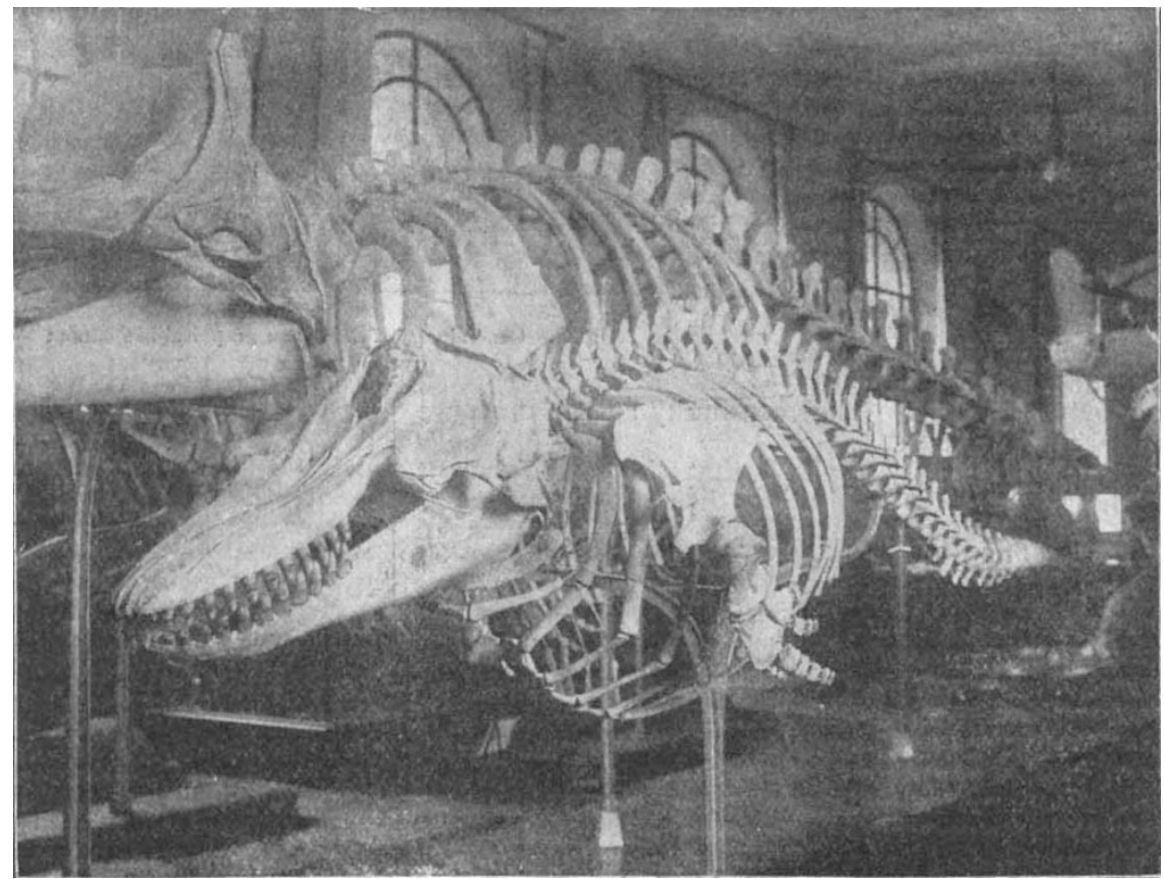

FIG. 3.-Skeleton of the great Crca killed by the Prince of Monaco near Monaco. NO. 2 I 4 O, VOL. 85$]$

result. The combat of the "thrasher" and the whale, so dear to the nautical mind, seems to be 
nothing but the violent and desperate resistance of the giant squid to being swallowed when brought to the surface by the cachalot.

The whalebone whale, shown in Fig. 6, was struck by the Prince in May, 1896 , not many miles from

these conditions the whale came up to breathe at regular intervals of between ten and eleven minutes the intervals between the spouts being the same almost to a second. This experiment supplies an important constant in the natural history of the whale. It

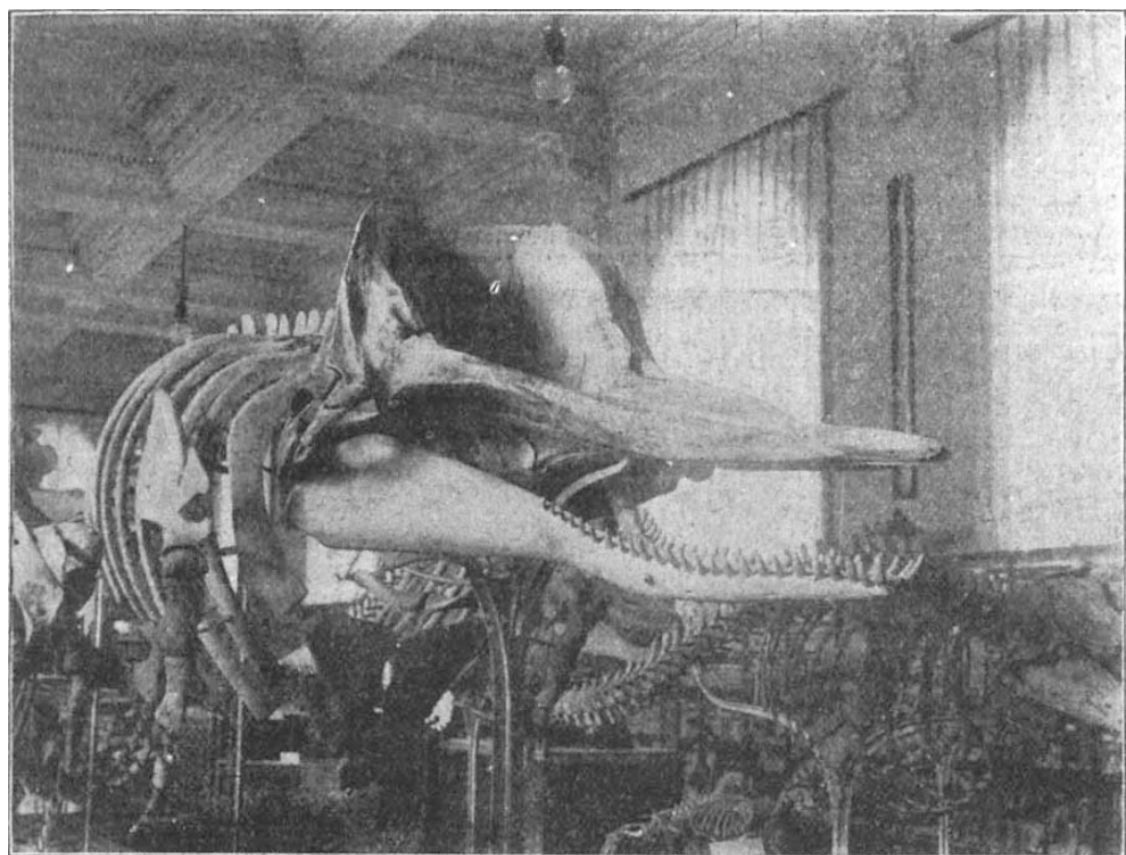

FIG. 4- -Skeleton of the Cachalot which furnished the fragments of gigantic Cephalopod, looks very simple, but it will not be readily repeated, except perhaps by the Prince himself. As the whale was on passage, it is unlikely that it went far below the surface. but there is abundant evidence that, in the search for food or to escape enemies, it penetrates to very considerable depths. In these excursions its body is exposed to rapid and considerable variations of pressure. These have to be borne by the structural frame of the animal, of which the ribs are an important part.

It is generally assumed that, before sounding, the whale fills its lungs with air, but this, being at atmospheric pressure, is of no use in assisting the body to resist the external pressure of a column of water equivalent, it may be, to many atmospheres. How the power of resist. ance is, in fact, provided, I am not anatomist enough to know, but it must be

Monaco, but it escaped. Its carcase was washed ashore in September of the same year, near Pietra Ligure, on the Italian Riviera. A remarkable feature of this skeleton is the evidence of fracture and repair of a number of ribs of its left side. This has been ascribed to collision with a steamer, but it is very unlikely that such an experience would leave its mark in nothing but a number of perfectly repaired ribs. It would seem to point to a type of accident to which whales are certainly exposed, and from which they perhaps not infrequently suffer.

'The habitat of the whale is the air and the water, and its functional economy has to be adapted to life in both elements, or rath $\leqslant r$, to life sometimes in the one, at other times in the other element.

In one of the Prince's recent cruises in the Mediterranean the yacht was found to be steaming in the wake of a whale, which was evidently making a passage, and in a leisurely way. The Prince seized the opportunity to follow the animal without pursuing it, and this was done with such slill that it remained unconscious of being followed. It kept a steady course, and, to "keep station" with it, the Princesse Alice had to steam at a speed of about ten knots. In NO. 2 I 4 O, VOL. 8.5 ! finite, and it is easy to imagine conditions in which the animal, whether in the pursuit of prey or in the endeavour to escape being made itself a prey, may strain it bevond its limits, and the ribs of one side, whichever is the weaker, may give way. In such an accident, beyond being broken, the ribs need not be seriously

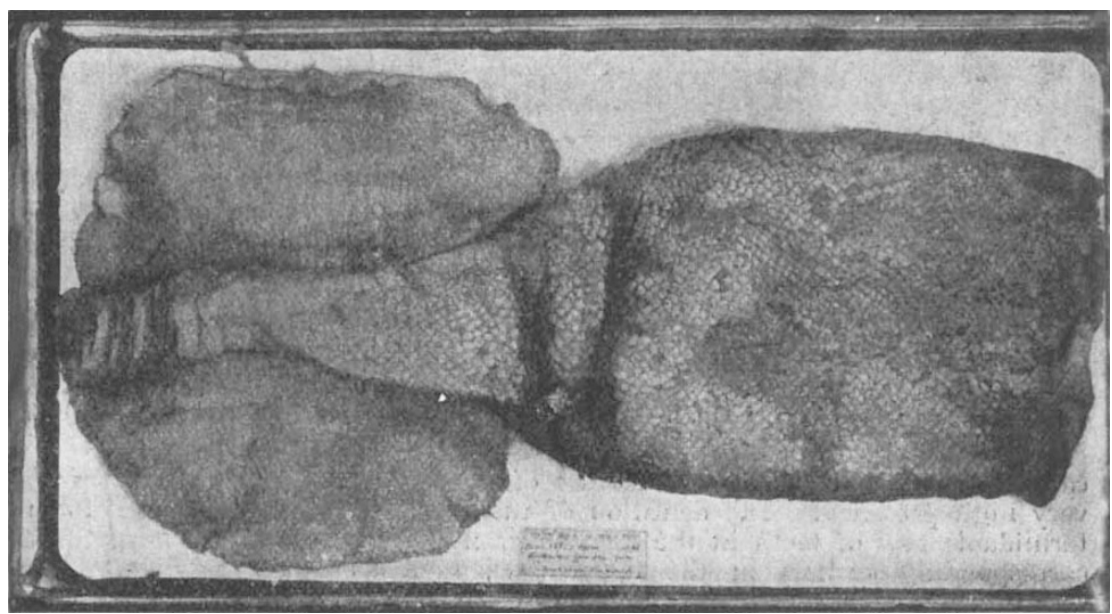

FIG. 5. The principal fragments of Lepidoteuthis Grimaldii. Joubin,

disturbed, and with the return to the surface or more moderate depths, they would fall into their places again, and that all the more easily because there is little or no pressure of one part on another, every part of the body of a totally immersed animal being 
water-borne. In such conditions recovery would be rapid and the joints perfect, as can be seen to be the case in the skeleton in the museum.

The accident to this whale is very suggestive. In a well-known experiment, Paul Bert reduced the pressure of the air in the lungs of a dog by a not very large fraction of an atmosphere, when the thorax immediately collapsed, every rib being broken. When a whale is struck and sounds, if only to a depth of one hundred metres, the pressure on its body is increased tenfold in a few seconds. How does its body stand it?

It is certain that the cachalot finds its prey in water of considerable depth. When it has seized it, of meteorology, a science which, especially as regards its application to the higher regions of the atmosphere, owes much to the participation of the Prince in its development. Until he directed his attention to ir, the ballons-sonde, carrying their freight of valuable instruments, were very frequently lost. Now, thanks to the method of keeping the "dead reckoning" of the balloon, developed and brought to perfection on the Princesse Alice, if it is followed for a few minutes during its ascent, it may disappear in the clouds, and its recovery, when it descends at sea, is almost a certainty. This department of investigation has been prosecuted outside the Mediterranean, and in the Prince's cruises of the

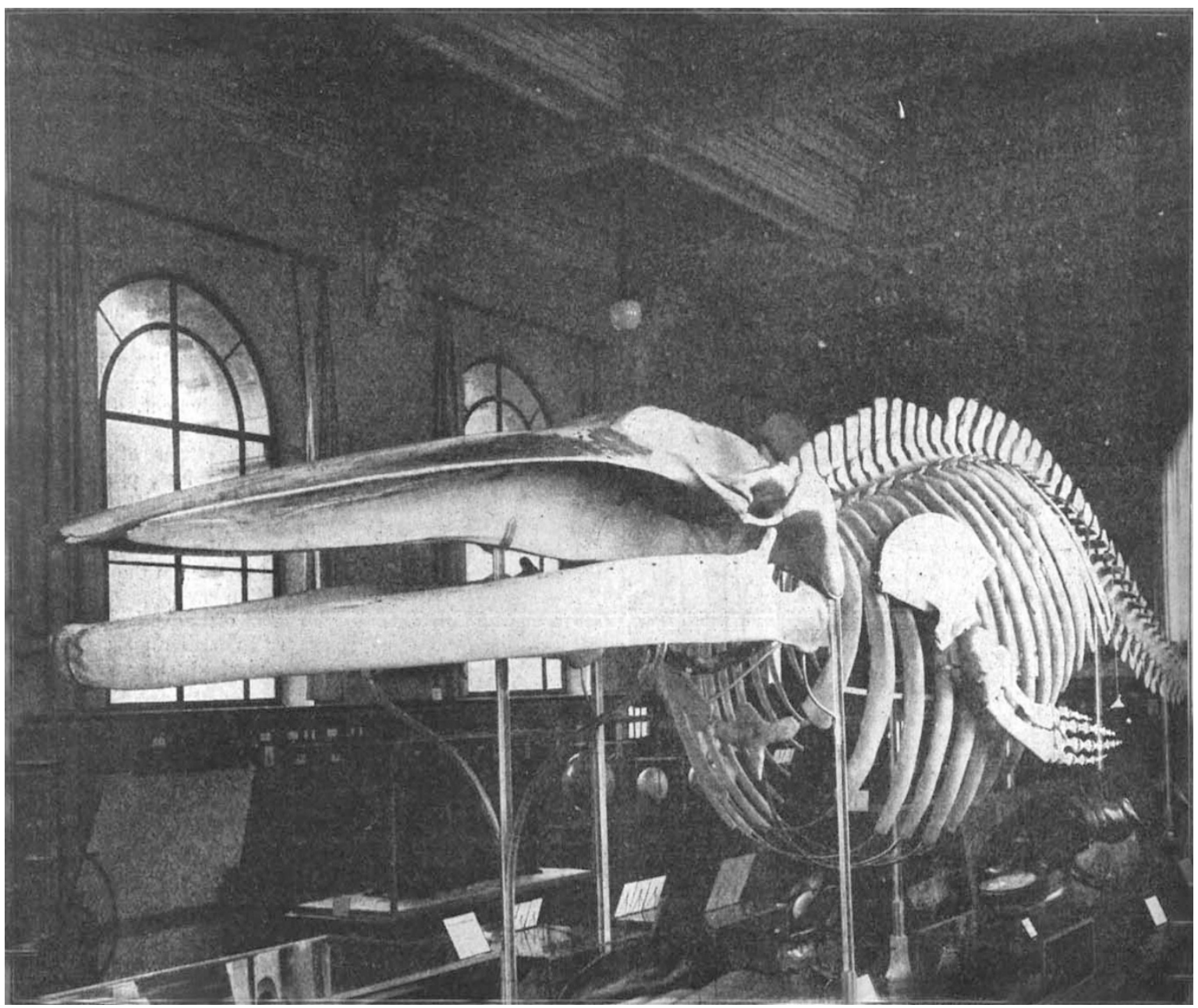

Fig. 6.-Skeleton of whalebone whale the ribs of which have been broken and mended.

can it swallow it in situ, in a medium of water under very high pressure? The dentition of this animal, a formidable row of teeth in the lower jaw fitting into corresponding sockets in the upper jaw, makes it certain that, when it has seized its prey it can hold it indefinitely. It has been observed that the cachalot sometimes takes its prey to the surface and swallows it there. Is this accidental or habitual? If habitual is it not another link with the far-back time when its habitat was the air and the land? These are some questions suggested by an attentive visit to the Museum of Monaco.

In the museum, room is provided for a department NO. 2140 , VOL. 85$]$ last two or three years it has been carried from the Cape Verde Islands in the heart of the tropics to the north of Spitsbergen, within five hundred miles of the Pole.

Besides the collections of animals and the instruments for their capture and study, there is in the lower part of the museum an aquarium, remarkable for its size and the completeness of its installation. This already commands a constant flux of visitors, chiefly the curious, but it is also frequented by men of science for serious study. It is already proposed to enlarge it considerably. The storey above the aquarium is divided into separate laboratories, fitied 
with a service of both fresh and sea water, and everything else required for chemical, physical, anc biological study. In these laboratories the occupant has all that a laboratory can supply, and at any time fresh material from the sea, collected by one of the small steam tenders of the museum.

Any notice of the museum of Monaco would be incomplete without an acknowledgment of what it owes to its director, Dr. Richard. None of the many men of science who have enjoyed the hospitality, either of the museum or the yacht, will require to be reminded of this, nor will they forget what they individually owe to Dr. Richard's never-failing courtesy and helpful aid. Personally, I have more thanks to offer than I can express for the countless services that he has rendered me during our friendship of twenty years. The Prince was fortunate in being able to attach him to his service in the early days of the Hirondelle. Since that time Dr. Richard has been his never-failing aid and assistant. It is not too much to say that without Dr. Richard's strenuous and unselfish work during these many years the museum with its rich collections and complete equipment would not be, as it is now, the greatest institution of the kind in the world.

J. Y. Buchanan.

\section{ENVIRONMENT VERSUS HEREDITY. ${ }^{1}$}

THE question of the assimilation of immigrants under American conditions has long been looked upon as of vital importance, and it has been mucis discussed, but heretofore with little accurate information. Speaking from general personal observation, people have thought that under the influence of the existing educational, social, and political conditions the immigrants gradually change their habits of life and their ways of thinking, and thus become Americans. The statement is often made that American citizens tend to resemble the American Indian, meaning thereby some generalised type of plains Indian, but this has never been put to scientific test. Little or no thought, however, has been given to the possible effect of the phvsical and social environment on the phvsical type of descendants of immigrants. The establishment by Congress of the Immigration Commission in February. 1907, gave the opportunity for a thorough investigation of the problems of immigration, and the inquiry into the anatomical characters of immigrants and their descendants was put under the direction of Prof. Franz Boas, of Columbia University, than whom no better selection could have been made. The present short report deals with only a portion of the material collected, but results obtained are of unexpected interest and importance.

The results so far worked out may be summarised as follows :-

r. The head form, which has always been considered as one of the most stable and permanent characteristics of human races, undergoes far-reaching changes due to the transfer of the races of Europe to American soil. The East European Hebrew, who has a very round head, becomes more long-headed; the south Italian, who in Italy has an exceedingly long head, becomes more short-headed; so that both approach a uniform type so far as the roundness of the head is concerned. Fig. I shows at $I$ and $I$ the cephalic index of foreign-born Hebrews and Sicilians; at 2 and 2 that of those born within ten vears after the arrival of their mothers in the United States; at 3 and 3 that of those born more than ten years after the

1 "Changes in Bodily Form of Descendants of Immigrants." The Im'nigration Committee, Dosument No. 203 presented to the 6rst Congress, and Session. (Washington, D.C., U.S.A., xgto.) NO. 2 I 40 , VOL. 85$]$ arrival of their mothers in the United States. The diagram shows the very rapid approach of the two types among children born shortly after the arrival of their mothers in America, and the slower continuation of this approach among those born later. Fig. 2 roughly indicates the general form of (1) the foreign-born Hebrew, (2) the foreign-born Sicilian, and (3) the average form of the head of the Americanborn Hebrew and Sicilian-born more than ten years after the arrival of the mother in America.

2. The influence of American environment upon the descendants of immigrants increases with the time that the immigrants have lived in the country before the birth of children.

3. The changes in head form consist in the increase of some measurements and in the decrease of others. The length of the head of Hebrews is increased; the width of the head and the width of the face are decreased. Among the Sicilians the length of the head is decreased, the width increased, but the width of the face is decreased.

4. The differences in type between the Americanborn descendant of the immigrant and the European-

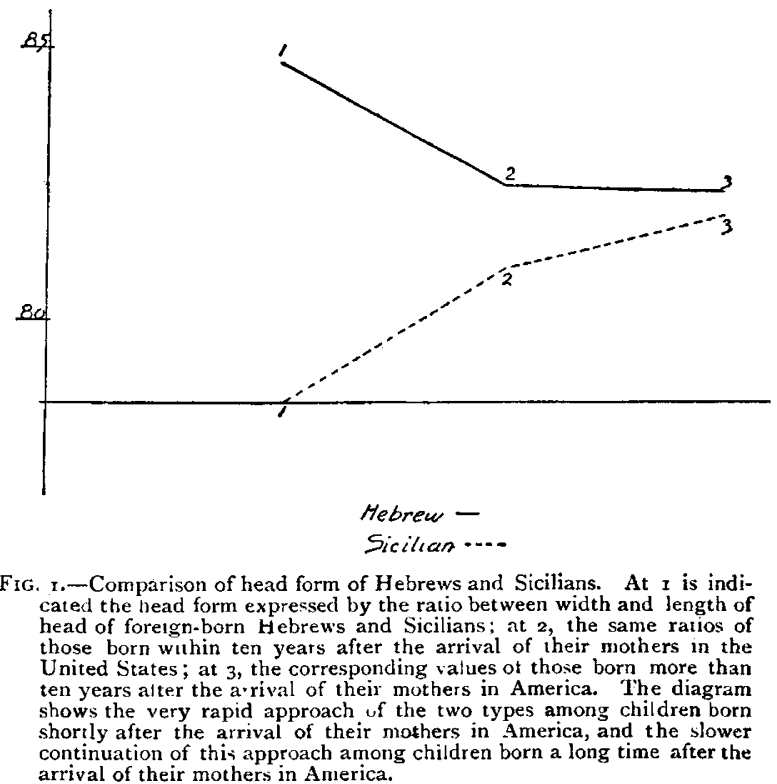

born immigrant develop in early childhood and persist throughout life.

5. Among the East European Hebrews the environment, even in the congested parts of the city, has brought about a general more favourable development of the race, which is expressed in the increased height of body (stature) and weight of the children. The Italian children, on the other hand. show no such favourable influence of American environment, but rather a small loss in vigour as compared to the average condition of the immigrant children; so that it appears that the south Italian race suffers under the influence of American city life, while the East European Hebrew develops under these conditions better than he does in his native country.

6. The type of the immigrant changes from year to year, owing to a selection which is dependent upon the economic conditions of the country. This is shown by the fact that after the panic of 1893 a sudden decrease in the general development of immigrants may be observed, which persisted for several years. A similar change seems to have taken place 